\title{
High sensitivity C-reactive protein: a biomarker for heart failure in children with univentricular heart disease
}

This article was published in the following Dove Press journal:

Current Biomarker Findings

28 August 2012

Number of times this article has been viewed

\author{
Alexander Lowenthal' \\ Luz Natal-Hernandez' \\ Shiri Lowenthal' \\ Nancy K Hills ${ }^{2}$ \\ Harold S Bernstein 1,3,4 \\ 'Department of Pediatrics, ${ }^{2}$ Clinical \\ and Translational Science Institute, \\ ${ }^{3}$ Cardiovascular Research Institute, \\ ${ }^{4}$ Eli and Edythe Broad Center of \\ Regeneration Medicine and Stem Cell \\ Research, University of California San \\ Francisco, San Francisco, CA, USA
}

Correspondence: Harold S Bernstein University of California San Francisco, 513 Parnassus Avenue, Box 1346, San Francisco, CA 94143-1346, USA

Tel + I 4I5 5028633

Fax +I 4154763075

Email harold.bernstein@ucsf.edu

\begin{abstract}
Children with univentricular congenital heart disease are at increased risk for developing heart failure. However, detecting early heart failure in these patients is especially difficult because few objective measures have been validated in this cohort. The aim of this study is to determine the usefulness of high sensitivity C-reactive protein (hsCRP) as a biomarker for detecting heart failure in univentricular heart disease patients, and to define the impact of univentricular morphology and stage of palliation on its utility. A cross-sectional observational study of children with univentricular congenital heart disease aged 1 month to 7 years was conducted. The presence of heart failure was defined as a Ross score $>2$. The association of hsCRP with heart failure was assessed using logistic regression and receiver operating characteristic curves. Of the 50 included children, $16(32 \%)$ had clinical heart failure. A doubling of hsCRP resulted in a 0.31 unit increase in Ross score $(95 \%$ confidence interval: $-0.07,0.56 ; P=0.01)$ with a c-statistic of $68 \%$. When stratified by ventricular morphology, the left univentricular morphology group exceeded the threshold of $\geq 75 \%$ (c-statistic $=81 \%$ ) as did those at stage II of palliation (c-statistic $=85 \%$ ). A cut point of $\geq 0.8 \mathrm{mg} / \mathrm{mL}$ correctly classified $75 \%$ of patients with left univentricular morphology, and $73 \%$ of patients regardless of morphology at stage II of palliation. From these results, we conclude that hsCRP is a useful biomarker of clinical heart failure in univentricular patients with left ventricular morphology at all stages of surgical palliation, and in all univentricular patients at stage II of palliation.
\end{abstract}

Keywords: congenital heart disease, single ventricle, heart failure, biomarker, high sensitivity C-reactive protein

\section{Introduction}

Children with univentricular congenital heart disease (UVD) have increased ventricular work and are at greater risk for developing heart failure (HF) than children with other congenital heart defects. Furthermore, the diagnosis of early or mild HF is especially difficult because there are few, if any, objective and quantitative measures of cardiac dysfunction that have been validated in this cohort. ${ }^{1}$ Many biomarkers have been studied extensively in adults with structurally normal hearts, however, whether these correlate with HF in infants and young children with UVD is not known. In adult HF, the etiology is typically coronary heart disease, whereas HF in children with UVD is presumed to be due to primary myocardial dysfunction. Furthermore, in the UVD patient, ventricular "cross talk" may be compromised or even absent. These important pathophysiological differences render it difficult to extrapolate adult data to pediatric UVD patients. In this study, we analyzed high sensitivity C-reactive protein (hsCRP) levels in 50 pediatric patients with UVD. We analyzed HF versus 
hsCRP based on ventricular morphology as well as stage of surgical palliation.

\section{Patients and methods Patients and study design}

A single site cross-sectional observational study utilizing a secondary study base was conducted. All children 1 month to 7 years old with UVD presenting to the UCSF Pediatric Heart Center between February 2007 and May 2010 were eligible for the study. Patients were excluded if they had renal failure, trisomy 21 , an acute intercurrent illness, a congenital defect that interfered with feeding (eg, cleft palate, esophageal atresia), or had participated in an investigational drug or device study in the last 6 months. In addition, patients for whom a valid Ross score could not be determined (eg, those receiving nasogastric tube feedings, those with postoperative diaphragmatic paralysis) were excluded. This study was approved by the UCSF Institutional Review Board, and written consent was obtained from the guardians of all subjects.

\section{Clinical heart failure scoring}

Each child was assigned an HF score based on the Ross classification system ${ }^{2}$ immediately prior to phlebotomy. The Ross classification relies on historical data, vital signs, and physical exam findings that were validated in infants, ${ }^{3-5}$ and has been adapted for children. ${ }^{3,46}$ For this study, HF scoring was recorded independent of presumed mechanism, since the goal was to identify biomarkers in UVD patients that would be clinically useful across etiologies. The primary outcome was HF (Ross class II-IV) versus no HF (Ross class I). Predictor measurement occurred subsequent to outcome determination, allowing assessors to be blinded to plasma protein levels.

\section{Plasma biomarker determination}

At the time of cardiac catheterization, pre-operative evaluation for cardiac surgery, or medical admission, $6 \mathrm{~mL}$ of whole blood was obtained in conjunction with clinically indicated phlebotomy. For hsCRP, $2 \mathrm{~mL}$ of whole blood was sent to the UCSF Clinical Laboratory for assay by rate turbidimetry. As a previously established negative control, ${ }^{7}$ cardiac troponin I (cTnI) was assayed from $2 \mathrm{~mL}$ of whole blood by fluorescent enzyme immunoassay. Each sample was assayed in duplicate. Additional data collected included patient name, medical record number, sex, age, weight, UVD morphology, diagnosis, and surgical history.

\section{Statistical analysis}

The primary outcome was HF (Ross class II-IV) versus no HF (Ross class I). The relationship between raw Ross score and plasma proteins was summarized using scatter plots, and analyzed using both linear and logistic regression. Univariate logistic regression was used to assess the crude association between hsCRP or cTnI levels and clinical HF. A $P$-value $<0.05$ was considered statistically significant. Receiver operator characteristic (ROC) curves were generated to evaluate proteins as biomarkers in the entire cohort and stratified groups. Assays were deemed useful if they carried a c-statistic $\geq 0.75$ (graph area encompassed by the curve). For a useful test, a clinically relevant cut point was identified that would distinguish UVD children in HF from those free of $\mathrm{HF}$ at the time of evaluation. All statistical analyses were performed using Stata software (v 10; StataCorp LP, College Station, TX).

\section{Results}

We approached 64 patients with UVD meeting the inclusion criteria for this study and presenting to the UCSF Pediatric Heart Center between February 2007 and May 2010 for enrollment. Ten (15\%) declined, and of the 54 remaining subjects, four $(5 \%)$ were subsequently excluded because of missing data. Thus, 50 children were studied (Table 1). Of those, 38 (76\%) had single morphologically right ventricles (RV), 11 (22\%) had single morphologically left ventricles $(\mathrm{LV})$, and one $(2 \%)$ had a primitive ventricle of indeterminate morphology. Of the single RV patients, 19 had hypoplastic left heart syndrome (ten with mitral and aortic atresia, two with mitral stenosis and aortic atresia, and seven with mitral and aortic stenosis), 12 had a right dominant (unbalanced) atrioventricular canal defect, three had double-outlet RV, two had interrupted aortic arch with a large ventricular septal defect and small LV, and there was one patient each with aortic stenosis and severe LV dysfunction, or L-transposition of the great arteries with severe pulmonary stenosis and a small LV. Of the 11 patients with single LV, five had tricuspid atresia, three had pulmonary atresia with intact ventricular septum, two had double-inlet LV, and one had critical pulmonary stenosis with a small RV. The patient with indeterminate ventricular morphology had a primitive ventricle with heterotaxy syndrome. While patients at stage I of palliation can be subject to volume overload contributing to HF because of the physiology associated with a Norwood or Sano procedure, pulmonary artery band, Blalock-Taussig shunt, or central shunt, later stages of palliation serve to unload the single ventricle and HF is more commonly due to 
Table I Patient data

\begin{tabular}{|c|c|c|c|c|c|c|}
\hline $\begin{array}{l}\text { Ventricular } \\
\text { morphology }\end{array}$ & $\begin{array}{l}\text { Stage } \\
\text { of palliation }^{\mathrm{a}}\end{array}$ & $\begin{array}{l}\text { Total } \\
\text { patients }\end{array}$ & Female/male & $\begin{array}{l}\text { Median age, } \\
\text { months (range) }\end{array}$ & $\begin{array}{l}\text { Ross } \\
\text { class I }\end{array}$ & $\begin{array}{l}\text { Ross } \\
\text { class II-IV }\end{array}$ \\
\hline \multirow[t]{4}{*}{ Right } & Total & 38 & $17 / 2 \mid$ & $20(2-80)$ & 26 & 12 \\
\hline & Stage I & 15 & $7 / 8$ & $4.4(2-6)$ & 10 & 5 \\
\hline & Stage II & 16 & $8 / 8$ & $35(5-54)$ & 11 & 5 \\
\hline & Stage III & 7 & $2 / 5$ & 7I (55-80) & 5 & 2 \\
\hline \multirow[t]{4}{*}{ Left } & Total & 11 & $4 / 7$ & $42(3-78)$ & 7 & 4 \\
\hline & Stage I & 3 & $\mathrm{I} / 2$ & $4(3-8)$ & 3 & 0 \\
\hline & Stage II & 7 & $3 / 4$ & 45 (17-69) & 3 & 4 \\
\hline & Stage III & I & $0 / 1$ & 73 & 1 & 0 \\
\hline \multirow[t]{4}{*}{ Indeterminate } & Total & 1 & I & $60(56-66)$ & 2 & 0 \\
\hline & Stage I & 0 & 0 & 0 & 0 & 0 \\
\hline & Stage II & 1 & $0 / 1$ & 66 & I & 0 \\
\hline & Stage III & 0 & 0 & 0 & 0 & 0 \\
\hline
\end{tabular}

Notes: aStage I: stabilization of aortic and pulmonary blood flow, eg, Norwood, Sano, pulmonary artery band, Blalock-Taussig shunt, central shunt; Stage II: establishment of partial cavopulmonary circulation between the superior vena cava and pulmonary arteries, eg, Glenn shunt, Kawashima; Stage III: completion of cavopulmonary circulation, eg, Fontan.

primary myocardial dysfunction. At our institution, patients with significant atrioventricular valvar insufficiency are not considered candidates for a cavopulmonary circulation.

Patients were assigned into a Ross class as a measure of clinical HF as previously described ${ }^{7,8}$ and the surgical stage of palliation was noted (Table 1). Of the 34 children free of clinical HF (Ross class I), the median Ross score was $1 \pm 0.8$. For the 16 children with clinical HF (Ross class II-IV), the median Ross score was $4.5 \pm 1.8$ (Ross class II). The overall prevalence of HF in the included sample was $32 \%$, with a morphology-specific prevalence of $32 \%$ in those with single RV and $36 \%$ in those with single LV.

Figure 1 shows scatter plots of hsCRP or cTnI versus Ross score that provide a visual appraisal of the linearity of the relationship between the candidate biomarkers and the Ross score. Notably, after $\log _{2}$ transformation, hsCRP demonstrated a linear relationship with the Ross score. A doubling of hsCRP resulted in a 0.31 unit increase in Ross score $(95 \%$ confidence interval $[\mathrm{CI}]:-0.07,0.56 ; P=0.01)$. As expected, cTnI $(0.1 \mathrm{mg} / \mathrm{L}$ increase associated with a 0.027 unit increase in Ross score [95\% CI: $-0.21,0.39, P=0.86]$ ) was not associated with increased Ross score in our sample. Exclusion of influential data points for these assays did not alter the results. Using single-predictor logistic regression, a doubling of hsCRP was associated with an odds ratio for HF of 1.41 (95\% CI: $1.03,1.92 ; P=0.03)$. cTnI (OR: $0.52,95 \%$ CI: $0.26,10.1 ; P=0.67$ ) was not associated with clinically relevant alterations in the odds of $\mathrm{HF}$.

ROC curve analysis of hsCRP data for the entire study cohort gave a c-statistic of $68 \%$, which came close to but did not exceed our pre-specified threshold of $\geq 75 \%$ area contained by the ROC curve (Figure 2). ROC analysis stratified by ventricular morphology demonstrated that the left UVD group exceeded the threshold of $\geq 75 \%$ (c-statistic $=81 \%$ ), however, right UVD patients did not (c-statistic $=59 \%$; Figure 3). ROC analysis stratified by stage of surgical palliation demonstrated that patients at stage II exceeded the usefulness threshold (c-statistic $=85 \%$ ), however, those at stages I and III did not (c-statistic $=38 \%$ and $50 \%$, respectively; Figure 3). As expected, cTnI failed to distinguish children in HF from those free of HF, with relatively poor sensitivities and specificities for HF (data not shown).

The test characteristics for various plasma levels of hsCRP as a marker of current clinical HF were examined for the single LV group and for all morphologies at stage II of palliation (those that demonstrated c-statistic values $\geq 75 \%$ ). For all patients with a single $\mathrm{LV}$, a cut point of $\geq 0.8 \mathrm{mg} / \mathrm{mL}$ showed both sensitivity (100\%) and specificity (63\%), thus correctly classifying $75 \%$ of the patients. When all UVD patients were stratified by stage of surgical palliation, a cut point of $\geq 0.8 \mathrm{mg} / \mathrm{mL}$ was also needed to correctly classify $73 \%$ of patients at stage II of palliation, with a sensitivity of $100 \%$ and a specificity of $57 \%$. Logistic regression, ROC curve analysis, and evaluation of test characteristics suggest that hsCRP can be a useful biomarker of mild to severe HF in single LV patients and all UVD patients at stage II of surgical palliation, with a cut point of $\geq 0.8 \mathrm{mg} / \mathrm{mL}$.

\section{Discussion}

In this study, we have demonstrated that hsCRP can be a useful biomarker of clinical HF in UVD patients with left ventricular morphology at all stages of surgical palliation, and in all UVD patients at stage II of palliation, with a cut point of $\geq 0.8 \mathrm{mg} / \mathrm{mL}$. To our knowledge, this is the first 


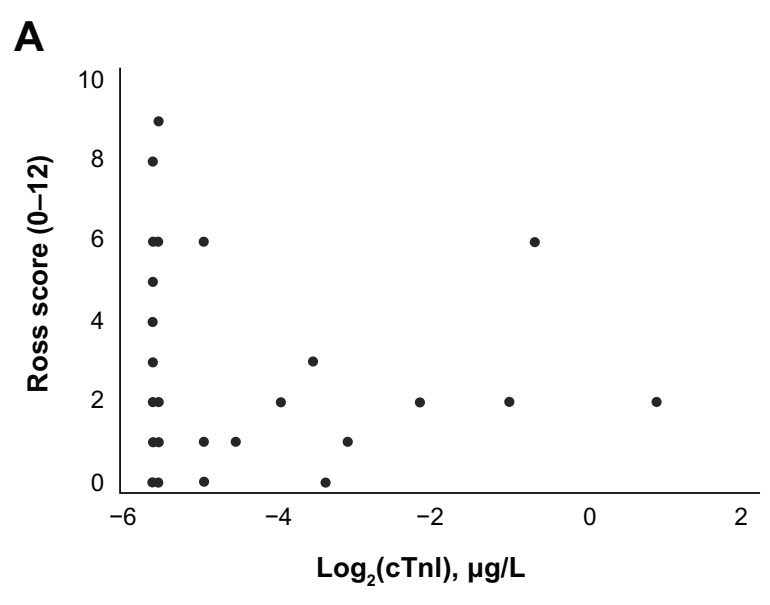

B

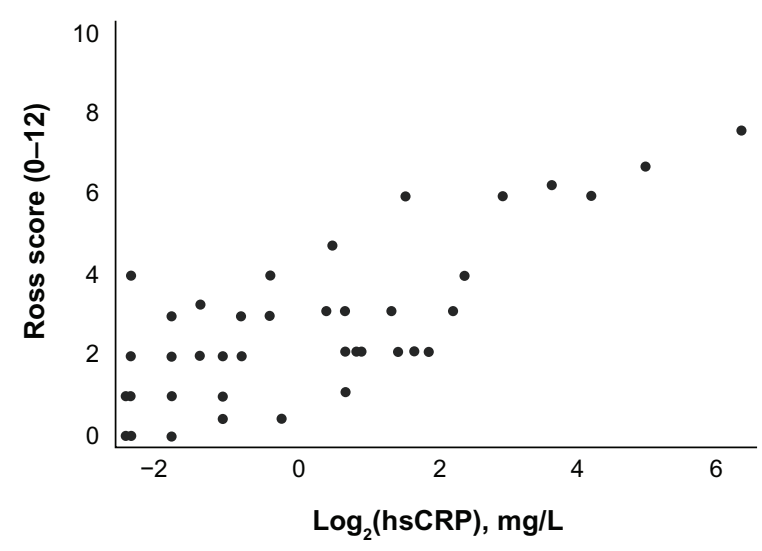

Figure I Evaluation of hsCRP and cTnl versus Ross scores. Scatter plot of plasma cTnl (A) and hsCRP (B) concentration versus raw Ross scores in 50 UVD patients. Note: $\log _{2}$ transformation of hsCRP revealed a roughly linear relationship with raw Ross score.

Abbreviations: hsCRP, high sensitivity C-reactive protein; cTnl, cardiac troponin I; UVD, univentricular congenital heart disease.

report of a relationship between hsCRP and clinical HF in young children with congenital heart disease, and UVD in particular.

In the pediatric population with normal cardiac anatomy, hsCRP has been helpful in distinguishing constrictive pericarditis from restrictive cardiomyopathy, ${ }^{9}$ infectious from non-infectious causes of fever following cardiopulmonary bypass, ${ }^{10}$ and has been shown to correlate with arterial stiffness ${ }^{11}$ and long-term sequelae ${ }^{12}$ in Kawasaki's disease. hsCRP also has been identified as a biomarker of acute and chronic HF in adults with ischemic heart disease. ${ }^{13}$ The mechanism has been thought to be due to the general inflammatory response that accompanies atherosclerotic plaque formation. ${ }^{14}$ Atherogenesis, however, is not a typical mechanism of HF in children with UVD. Recent studies suggest that this may not be the only source of C-reactive protein elevation. Anzulovic-Mirosevic et al have shown that C-reactive protein levels are increased in adult patients with non-ischemic

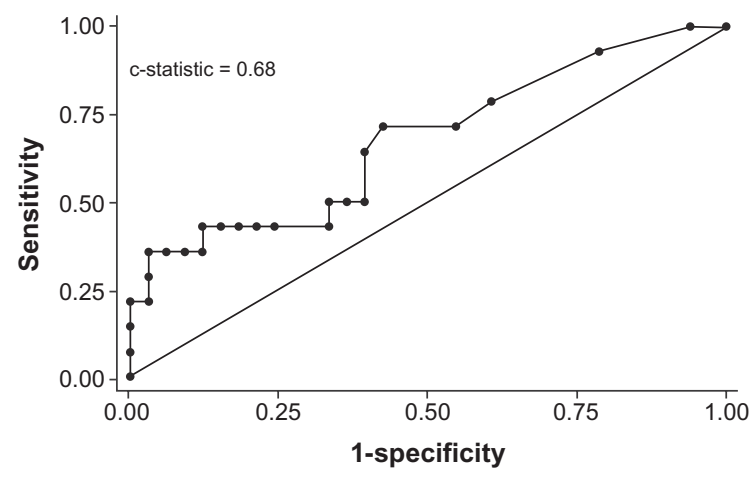

Figure 2 Receiver operator characteristic curve for hsCRP in UVD patients. Notes: False positives (I-specificity) were plotted against true positives (sensitivity) for all patients. The area under the curve (c-statistic) was 0.68 , which approached significance. Abbreviations: hsCRP, high sensitivity C-reactive protein; UVD, univentricular congenital heart disease.

cardiomyopathy proportionate to the severity of the symptoms and systolic impairment. ${ }^{15}$ Furthermore, in situ hybridization experiments have shown significant myocardial production of C-reactive protein mRNA in cardiomyocytes of patients with non-ischemic cardiomyopathy. ${ }^{16}$

Interestingly, hsCRP in UVD patients was found to be more indicative of HF in those patients with left ventricular morphology and those at the second stage of palliation. This is a particularly important time during staged palliation of UVD because patients with a partial cavopulmonary connection are relatively stable from a hemodynamic standpoint, and early detection of cardiac dysfunction by elevated hsCRP levels might guide planning for completion of the cavopulmonary connection (ie, Fontan), as well as facilitate risk stratification. For the patients included in this study, the median ages at stages II and III palliation were 5.3 months (range 2.8-13.5 months) and 4.3 years (range 1.5-6.6 years), respectively; however, early detection of heart failure could prompt an accelerated timeline for unloading the ventricle and more aggressive medical optimization prior to surgery for individual UVD patients.

An acknowledged limitation of this study is the use of the Ross classification system for HF, which has not been specifically validated in the UVD population. However, it has been utilized extensively in pediatric HF studies, ${ }^{6}$ including the multicenter trials of carvedilol therapy for pediatric HF that included UVD patients, ${ }^{17-19}$ and enalapril in infants with UVD. ${ }^{17-21}$ As such, we considered it the most relevant outcome measure for this study.

In conclusion, we show that a hsCRP cut point value of $\geq 0.8 \mathrm{mg} / \mathrm{mL}$ is associated with HF specifically in those UVD patients at the second stage of surgical palliation, implying that hsCRP provides a useful tool with which to monitor HF in this unique population. We believe that this 

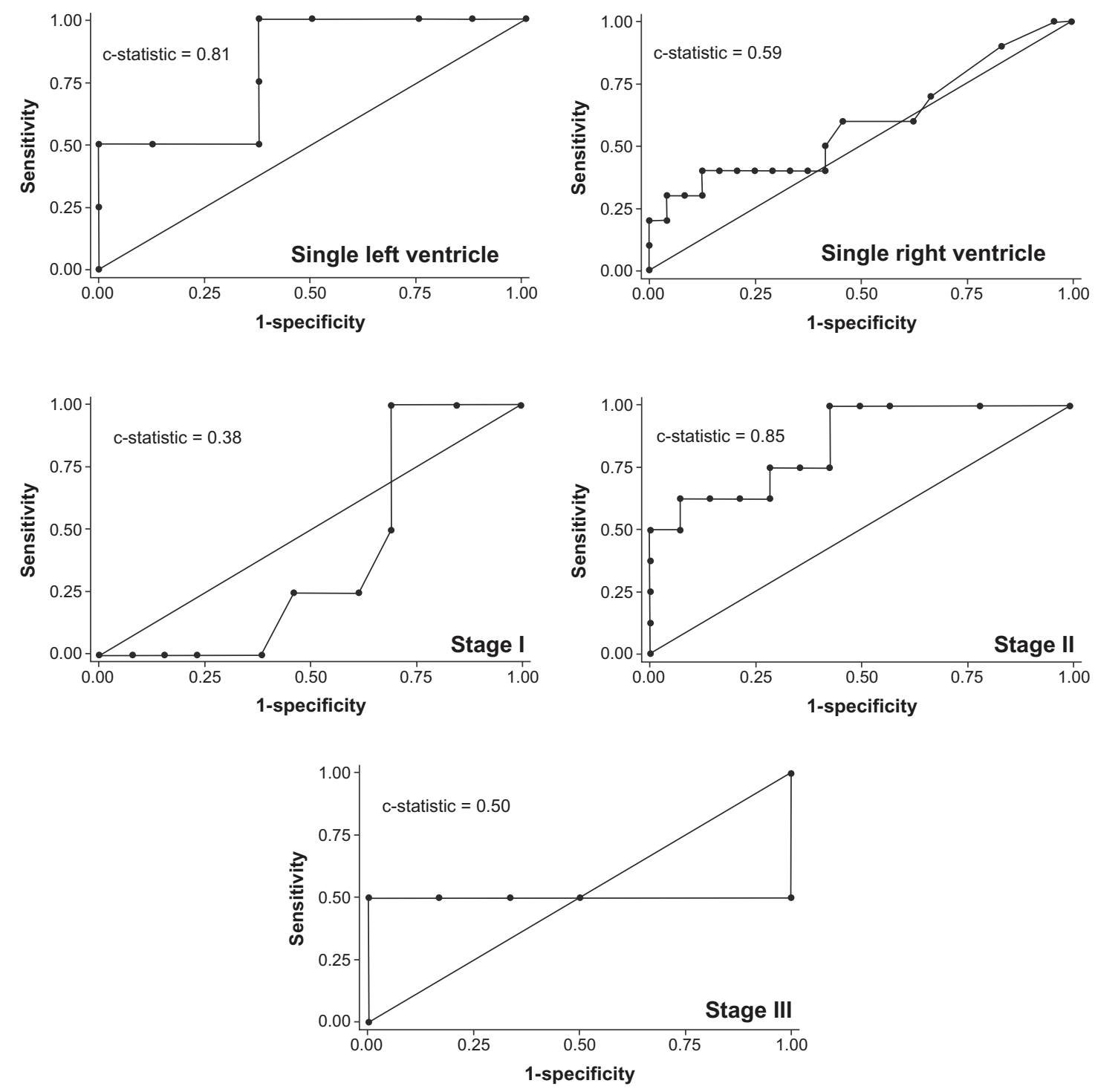

Figure 3 Receiver operator characteristic curves for hsCRP by patient group.

Notes: False positives (I-specificity) were plotted against true positives (sensitivity) for patients with single left or right ventricle, and for patients with single ventricles who had undergone Stage I (Norwood, Sano, pulmonary artery band, Blalock-Taussig shunt, or central shunt), Stage II (partial cavopulmonary shunt, ie, Glenn or Kawashima), or Stage III (complete cavopulmonary shunt, ie, Fontan) surgeries. Patient groups with a single left ventricle at any stage of surgical palliation, and all patients at stage II of palliation, demonstrated an area under the curve (c-statistic) $\geq 0.75$, indicating a useful test.

Abbreviation: hsCRP, high sensitivity C-reactive protein.

value should form the basis of future longitudinal studies to determine the value of hsCRP in monitoring the severity of $\mathrm{HF}$, and the ability of hsCRP to predict cardiac dysfunction and other important clinical outcomes.

\section{Acknowledgments}

The authors thank the UCSF pediatric cardiology fellows and the UCSF Congenital Cardiac Catheterization Laboratory staff for their invaluable assistance with the study.

\section{Disclosure}

Financial support was received from the Lorraine Newman Fund of the UCSF Division of Pediatric Cardiology and a Strategic Opportunity Award from the UCSF Clinical and Translational Science Institute (National Institutes of Health RR024131) to HSB.

\section{References}

1. Shaddy RE, Webb G. Applying heart failure guidelines to adult congenital heart disease patients. Expert Rev Cardiovasc Ther. 2008;6(2):165-174.

2. Hsu DT, Pearson GD. Heart failure in children: part I: history, etiology, and pathophysiology. Circ Heart Fail. 2009;2(1):63-70.

3. Johnstone DE, Abdulla A, Arnold JM, et al. Diagnosis and management of heart failure. Canadian Cardiovascular Society. Can J Cardiol. 1994;10(6):613-631, 635-654.

4. Rosenthal D, Chrisant MR, Edens E, et al. International Society for Heart and Lung Transplantation: Practice guidelines for management of heart failure in children. J Heart Lung Transplant. 2004;23(12):1313-1333. 
5. Ross RD, Bollinger RO, Pinsky WW. Grading the severity of congestive heart failure in infants. Pediatr Cardiol. 1992;13(2):72-75.

6. Ross RD. The ross classification for heart failure in children after 25 years: a review and an age-stratified revision. Pediatr Cardiol. 2012. [Epub ahead of print.].

7. Shah A, Feraco AM, Harmon C, Tacy T, Fineman JR, Bernstein HS. Usefulness of various plasma biomarkers for diagnosis of heart failure in children with single ventricle physiology. Am J Cardiol. 2009;104(9):1280-1284.

8. Lowenthal A, Camacho BV, Lowenthal S, et al. Usefulness of B-type natriuretic Peptide and N-terminal pro-B-type natriuretic Peptide as biomarkers for heart failure in young children with single ventricle congenital heart disease. Am J Cardiol. 2012;109(6):866-872.

9. Karaahmet T, Yilmaz F, Tigen K, Mutlu B, Cevik C, Basaran Y. Diagnostic utility of plasma N-terminal pro-B-type natriuretic peptide and C-reactive protein levels in differential diagnosis of pericardial constriction and restrictive cardiomyopathy. Congest Heart Fail. 2009;15(6):265-270.

10. Nahum E, Livni G, Schiller O, Bitan S, Ashkenazi S, Dagan O. Role of C-reactive protein velocity in the diagnosis of early bacterial infections in children after cardiac surgery. $J$ Intensive Care Med. 2012;27(3):191-196.

11. Cheung YF, Ho MH, Tam SC, Yung TC. Increased high sensitivity $\mathrm{C}$ reactive protein concentrations and increased arterial stiffness in children with a history of Kawasaki disease. Heart. 2004;90(11): 1281-1285.

12. Mitani Y, Sawada H, Hayakawa H, et al. Elevated levels of highsensitivity C-reactive protein and serum amyloid-A late after Kawasaki disease: association between inflammation and late coronary sequelae in Kawasaki disease. Circulation. 2005;111(1):38-43.
13. Windram JD, Loh PH, Rigby AS, Hanning I, Clark AL, Cleland JG. Relationship of high-sensitivity C-reactive protein to prognosis and other prognostic markers in outpatients with heart failure. Am Heart $J$. 2007;153(6):1048-1055.

14. Pepys MB, Hirschfield GM. C-reactive protein: a critical update. J Clin Invest. 2003;111(12):1805-1812.

15. Anzulovic-Mirosevic D, Razzolini R, Zaninotto M, et al. The C-reactive protein levels in left ventricular dysfunction of different etiology. Inflamm Allergy Drug Targets. 2009;8(4):247-251.

16. Satoh M, Nakamura M, Akatsu T, Shimoda Y, Segawa I, Hiramori K. $\mathrm{C}$-reactive protein co-expresses with tumor necrosis factor-alpha in the myocardium in human dilated cardiomyopathy. Eur J Heart Fail. 2005;7(5):748-754.

17. Ratnasamy C, Kinnamon DD, Lipshultz SE, Rusconi P. Associations between neurohormonal and inflammatory activation and heart failure in children. Am Heart J. 2008;155(3):527-533.

18. Shaddy RE, Boucek MM, Hsu DT, et al. Carvedilol for children and adolescents with heart failure: a randomized controlled trial. JAMA. 2007;298(10):1171-1179.

19. Yeh JL, Hsu JH, Dai ZK, Liou SF, Chen IJ, Wu JR. Increased circulating big endothelin-1, endothelin-1 and atrial natriuretic peptide in infants and children with heart failure secondary to congenital heart disease. Int J Cardiol. 2005;104(1):15-20.

20. Hsu DT, Zak V, Mahony L, et al. Enalapril in infants with single ventricle: results of a multicenter randomized trial. Circulation. 2010;122(4):333-340.

21. Hsu DT, Mital S, Ravishankar C, et al. Rationale and design of a trial of angiotensin-converting enzyme inhibition in infants with single ventricle. Am Heart J. 2009;157(1):37-45.
Current Biomarker Findings

\section{Publish your work in this journal}

Current Biomarker Findings is an international, peer-reviewed, open access journal publishing original research, reports, reviews and commentaries on all areas of biomarker research. The manuscript management system is completely online and includes a very quick and fair

\section{Dovepress}

peer-review system. Visit http://www.dovepress.com/testimonials.php to read real quotes from published authors. 